\section{Our changing environment}

RalphJ. Cicerone

Atmospheric Change: An Earth System Perspective. By T. E. Graedel and P. J. Crutzen. W. H. Freeman: 1993. Pp. 446. £35.95, \$42.95 (hbk); £16.95, \$32.95 (pbk).

'EARTH system science' is a term being adopted by teachers and researchers who are concerned with more than just oceanography, meteorology, hydrology and surface geology, and who are attempting to understand environmental changes due to natural and human-induced disturbances. The agenda of Earth system science includes estimating how global and regional climates and biota will change as a result of the infrared radiative 'forcing' from increased concentrations of greenhouse gases in the atmosphere; the extent of present and future ozone-layer losses and the effects of increased ultraviolet light dosages on humans and other organisms; how air, oceans and soils are changing as humans accelerate their manipulations of the cycles of several nutrient elements such as nitrogen, sulphur and phosphorus; and how volcanoes affect atmospheric chemistry and the Earth's climate. Despite the increasing importance of such questions, a scientific framework for their investigation has been difficult to construct. Although much progress has been made through disciplines such as physical oceanography or atmospheric chemistry, many feedbacks are obvious in the system and some broader framework is needed. Probably the only integrated concept of the whole system's behaviour is Gaia from James Lovelock; Gaia has demonstrated the importance of the biota but it is not serving as the general prism through which all physical, chemical and biological phenomena and today's questions can be viewed by Earth scientists.

Graedel and Cruzten's book, subtitled "An Earth System Perspective" does an amazing job of introducing the reader to the large-scale issues of today and the future, and to the chemistry, physics and (less so) biology that will determine how the system responds. The book's scope and its range of examples impress on the reader the scientific challenge ahead and also the intellectual breadth of the authors. In discussion of aquatic phenomena, for example, an enormous range of concentrations, oxidation states and anions and cations is observed in waters from rain, clouds, fog, dew, groundwater, oceans and brines; both thermodynamic and kinetic analyses are used to make sense of these arrays. Similarly, palaeorecords such as those of gases trapped in ice cores are introduced to estimate the limits and the timescales of past Earth changes. Interesting measurement records are pre- sented from around the world; Earth system science knows no boundaries (and the authors seem aware of the best data regardless of their source). Spatial scales in physical phenomena from global to subatomic are involved in atmospheric and environmental change, as are many temporal scales; the authors present modelling approaches to take these into account as they synthesize, explain and attempt to predict future changes. The book is accurate and careful throughout: for example, the dot notation is used to denote free radicals, a practice that is neglected in most other books and journal articles. In almost all cases, data are also up to date.

Who will use this book? It would be best for a course (with the same title as the book) for motivated, advanced undergraduates, intended to provide a foundation and broad context for further evaluations of human impacts and of the limits of stability of the natural system. Such a course would be at least 15 weeks long. Because of its emphasis on issues, I think that Atmospheric Change is more motivating than Global Biogeochemical Cycles (eds S. S. Butcher et al., Academic Press, 1992). Alternatively, parts of the book could serve as text material for a briefer course on atmospheric and environmental chemistry.

The authors express concern about human population growth and poor environmental stewardship. Given that scientific data and understanding are necessary to deal with these issues, and that excellent books contribute to this knowledge, the authors have done their share toward solving our problems.

Ralph J. Cicerone is in the Earth System Science Department, University of California, Irvine, California 92717-3100, USA.

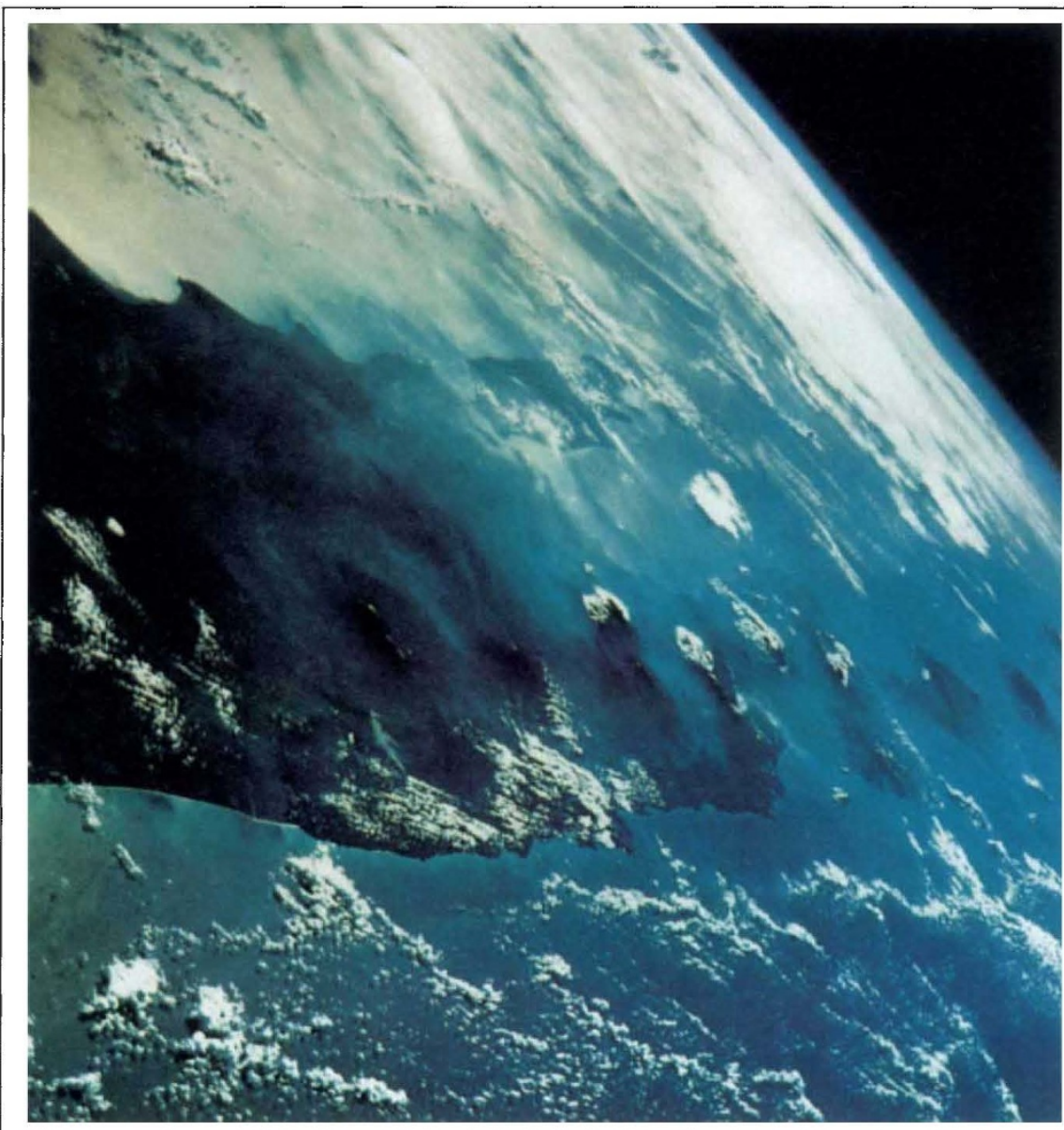

THIS view of a remote volcanic island chain in Eastern Java was taken from the Space Shuttle in 1985. Observations from space are often the best way of learning which volcanic gases and aerosols are injected into the atmosphere, the thermal structure and volume of active lava flows, and the deformation history of volcanic cones and craters. The picture is taken from Atlas of Satellite Observations Related to Global Change edited by R. J. Gurney, J. L Foster and C. L Parkinson, a richly illustrated account for a general scientific audience. Cambridge University Press, £35, \$49.95. 